
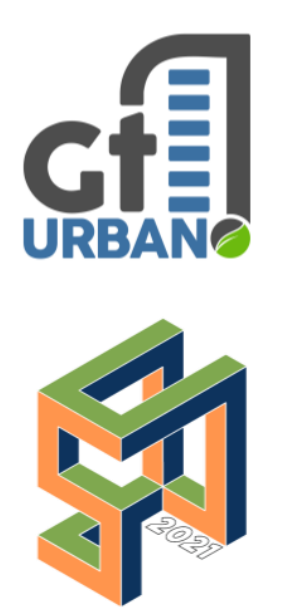

SINGEURB

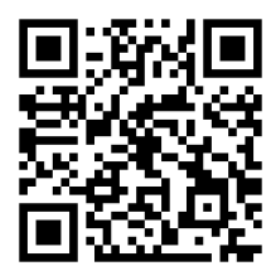

Como citar:

RICCHEZZA, Leonardo; CORRÊA, Roberto. Usina solar urbana: uma análise do potencial fotovoltaico de armazéns logísticos como miniusinas solares urbanas. In: III SIMPÓSIO NACIONAL DE GESTÃO E ENGENHARIA URBANA: SINGEURB, 2021, Maceió. Anais... Porto Alegre: ANTAC, 2021. p. 114-123.

Disponível em: https://eventos.antac.o rg.br/index.php/singe urb/issue/view/14

\title{
Usina solar urbana: uma análise do potencial fotovoltaico de armazéns logísticos como miniusinas solares urbanas
}

\author{
Urban solar plant: an analysis of the photovoltaic \\ potential of logistic warehouses as mini urban \\ solar plants
}

Leonardo Ricchezza, Universidade Federal do Rio de Janeiro, leonardoricchezza@poli.ufrj.br

Roberto Corrêa, Universidade Federal do Rio de Janeiro, roberto@poli.ufrj.br

\section{RESUMO}

A diversificação das fontes de energia na matriz elétrica se torna importante a partir da consolidação das intensas variações climáticas que prejudicam as hidrelétricas, que geram nas regiões Centro-Oeste e Sudeste quase metade da energia elétrica do país, concentrando nas áreas urbanas, os maiores consumidores. Diferente de outros armazéns de mesma área mas ocupações distintas, Armazéns Logísticos podem potenciar a distribuição de energia devido às suas características particulares, como grandes coberturas e baixo consumo, criando excedente elétrico. Desta forma, contribuem com a diversidade da matriz elétrica, criam sinergia com o setor logístico urbano, reduzem perdas com linhas de transmissão, bem como os gases de efeito estufa, e ainda utilizam espaços prontos junto aos consumidores. Assim, este estudo de caso apresenta as características de consumo de um Armazém Logístico, baseado na fatura de energia, e o dimensionamento de um sistema solar a ser instalado no edifício. O objetivo foi investigar, através de simuladores para dimensionamento de sistemas fotovoltaicos, a capacidade de criar excedente elétrico que possa ser injetado na rede para distribuição. Os resultados confirmaram a possibilidade desses edifícios serem usados como Usinas Fotovoltaicas Urbanas, contribuindo com a sustentabilidade do sistema elétrico e com o planejamento da infraestrutura urbana.

Palavras-chave: Energias Renováveis, Usina Fotovoltaica, Armazém Logístico, Excedente Elétrico.

\begin{abstract}
Diversification of energy sources in the eletricity matrix becomes particularly important following the consolidation of intense climatic variations, damaging hydroelectric plants, which account for more than half of Brazil's energy generation, which in the Midwest and Southeast generate almost half of the country's electricity, and concentrate the largest consumers in its urban areas. Differently from other warehouses with the same area and different uses, Logistic Warehouses can strengthen the distribution of energy due to their particular characteristics, such as large roofs and low energy demands, creating excess
\end{abstract}


electricity. In this way, contribute to the electricity matrix's diversity, act in synergy with the urban logistics sector, reduce transmission line's loss as well as greenhouse gases, and use ready-made spaces close to the consumer. Therefore, this case study presents the consumption characteristics of a Logistic Warehouse, based on the energy bill, and planning a solar system to be installed in the building. The aim was to investigate, through simulations of photovoltaic systems, the capacity for generating excess energy to be injected back into the distribution network. The results confirm the possibility of using these buildings as Urban Photovoltaic Plants, contributing to the system's sustainability e to urban infrastructure planning.

Keywords: Renewable Energy, Solar Plant, Logistic Warehouse, Excess Electricity.

\section{INTRODUÇÃO}

A percentagem da população urbana no mundo cresce a cada ano. No Brasil, segundo dados do IBGE (2013), a concentração da população nos centros urbanos chegou a 84,36\% em 2010, tendo a região sudeste, o maior percentual.

De acordo com o Ministério de Minas e Energia (MME, 2020), a matriz elétrica brasileira tem o predomínio de fontes renováveis com $81,9 \%$, onde as hidrelétricas contribuem com $64,4 \%$, e a fonte solar participa com $1 \%$.

Desde 1996, o Brasil já atravessou duas grandes crises hídricas afetando diretamente a oferta de energia elétrica. Suscetíveis às variações climáticas, em 2001 as hidrelétricas apresentaram níveis críticos, causando racionamento de energia. Em 2015, recordes de seca desabasteceram as hidrelétricas das regiões sudeste e centro-oeste, responsáveis por 70\% da oferta de energia elétrica por fonte hídrica (MME, 2020).

Como essas variações climáticas "tendem a ser mais frequentes e mais severas, podendo afetar de forma permanente a produção de energia" (PBMC, 2016, p.42), como mostra a Figura 1, é necessário diversificar as fontes da matriz elétrica. Assim, considerando o enorme potencial fotovoltaico brasileiro, usinas solares em armazéns logísticos tornam-se aliados estratégicos na oferta de energia renovável junto aos grandes centros consumidores.

A escolha dos Armazéns Logísticos para produção de energia fotovoltaica se deu por possuírem características particulares diferente de outros armazéns. Possuem grandes áreas de telhado e baixo consumo elétrico. Desta forma, este estudo de caso tem por objetivo investigar o potencial fotovoltaico de Armazéns Logísticos, cujo excedente de energia possa ser injetado na rede para distribuição. 
Figura 1 - Energia armazenada em \% da capacidade máxima dos reservatórios das usinas hidrelétricas das regiões sedeste e centro-oeste

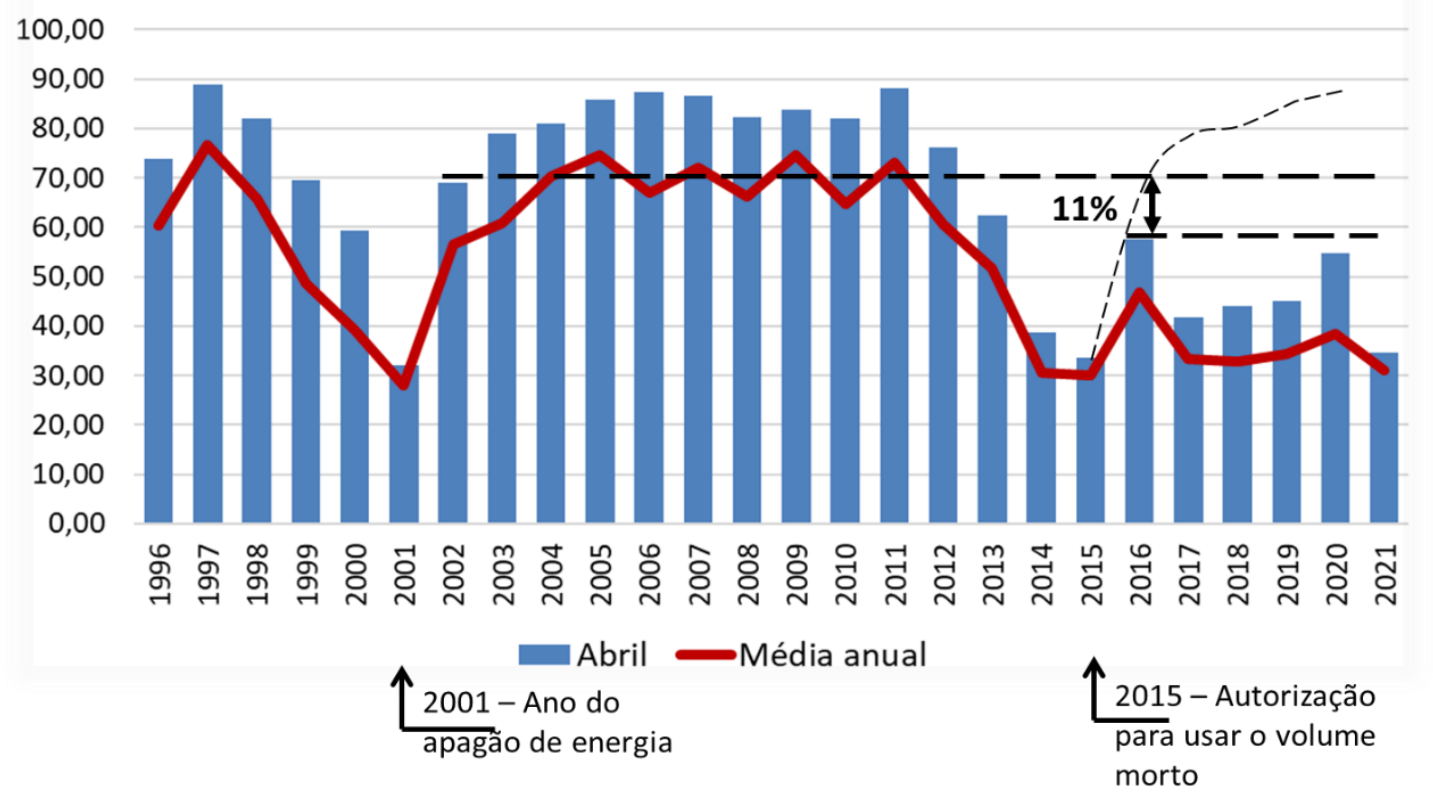

Fonte: Adaptado pelo autor (ONS, 2021)

\section{METODOLOGIA}

O estudo de caso parte da utilização dos softwares Meteonorm 7.3 e PVsyst 7.1 que atuam em conjunto. O primeiro é um banco de dados climáticos que agrega mais de 8.000 estações meteorológicas de 5 satélites geoestacionários para modelagens climatológicas, calculando a irradiação solar horária a partir de informações de tempo e clima no local da instalação. O segundo, faz os cálculos da geração e do excedente de energia fotovoltaica a partir dos dados fornecidos pelo Meteonorm 7.3, de parâmetros geográficos como, posição, área disponível e escolha dos equipamentos e do consumo elétrico. Calcula a energia nominal gerada, as perdas no sistema, a energia útil consumida, a energia compensada e o excedente elétrico para distribuição.

O estudo consiste em dimensionar um sistema fotovoltaico para um Armazém Logístico, determinando seu potencial de geração de energia solar, comparar com sua energia consumida, calcular a energia elétrica excedente que possa ser distribuída na rede e estimar quantas residências poderiam ser atendidas.

\subsection{O objeto de estudo}

O Armazém Logístico, objeto para análise da cobertura como miniusina fotovoltaica, está inserido numa região que agrupa armazéns do mesmo tipo. Está localizado no bairro da Pavuna, entre duas principais vias de acesso à cidade do Rio de Janeiro, a Rodovia Presidente Dutra e a Via Expressa Presidente João Goulart (Linha Vermelha), em destaque na Figura 2. 
Figura 2 - Localização do armazém logístico

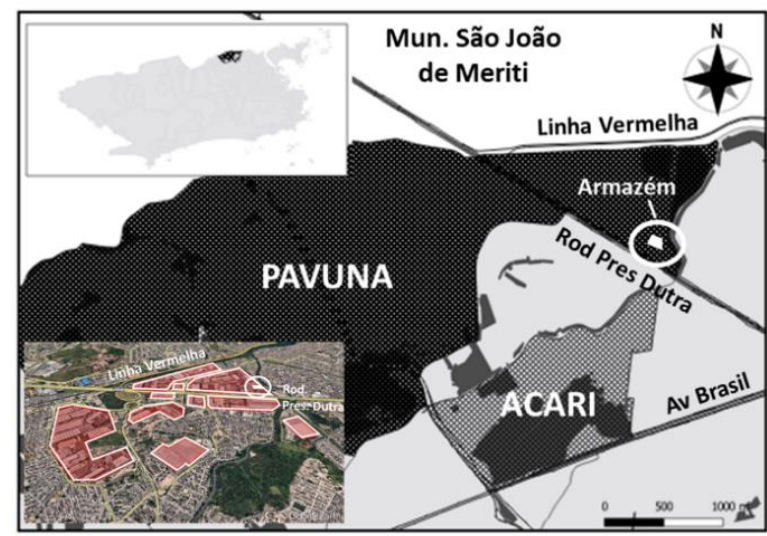

Fonte: Autor (2021)

A área disponível para instalação da miniusina será a cobertura do armazém mostrado na Figura 3. De acordo com os projetos arquitetônicos apresentados na Figura 4, o telhado totaliza $7.844,41 \mathrm{~m}^{2}$ no plano inclinado.

Figura 3 - Telhado do armazém logístico

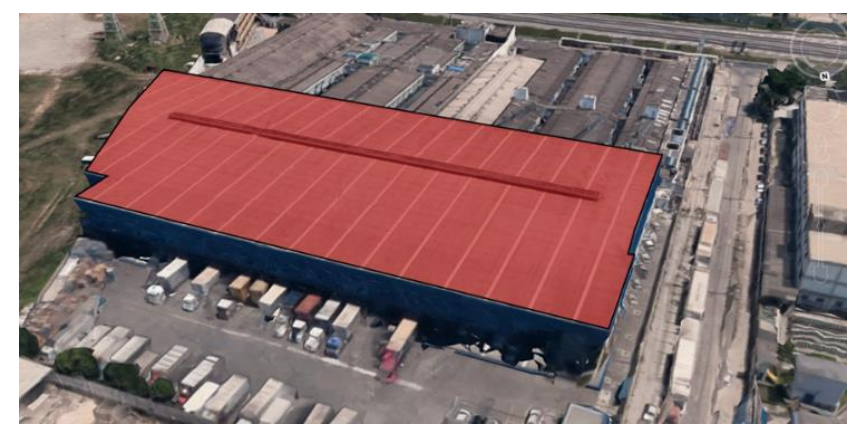

Fonte: Google Earth (2021)

O telhado possui dois caimentos, rotacionados $31^{\circ}$ do norte geográfico (desvio azimutal), um voltado a $31^{\circ}$ da face norte, a melhor situação para geração solar, e o outro voltado a $31^{\circ}$ da face sul, a pior situação. $\mathrm{O}$ angulo de inclinação ideal das placas fotovoltaicas é igual à latitude do local, que para o Armazém é de $22^{\circ} 48^{\prime} 36^{\prime \prime}$ Sul. Contudo, a inclinação dos dois caimentos do telhado é de $4^{\circ}$ (Figura 4). Como opção, as placas fotovoltaicas poderiam ser instaladas sobre suporte posicionando-as na inclinação ideal, mas isso não será considerado.

O telhado é formado por telhas metálicas intercaladas com telhas translúcidas, iluminando o armazém internamente com luz natural, que não podem ser sobrepostas pelas placas solares. Também é necessária uma área livre de circulação para acesso aos módulos e à manutenção do telhado. 
Figura 4 - Características geométrica e de posicionamento do telhado do armazém logístico e posicionamento dos módulos fotovoltaicos

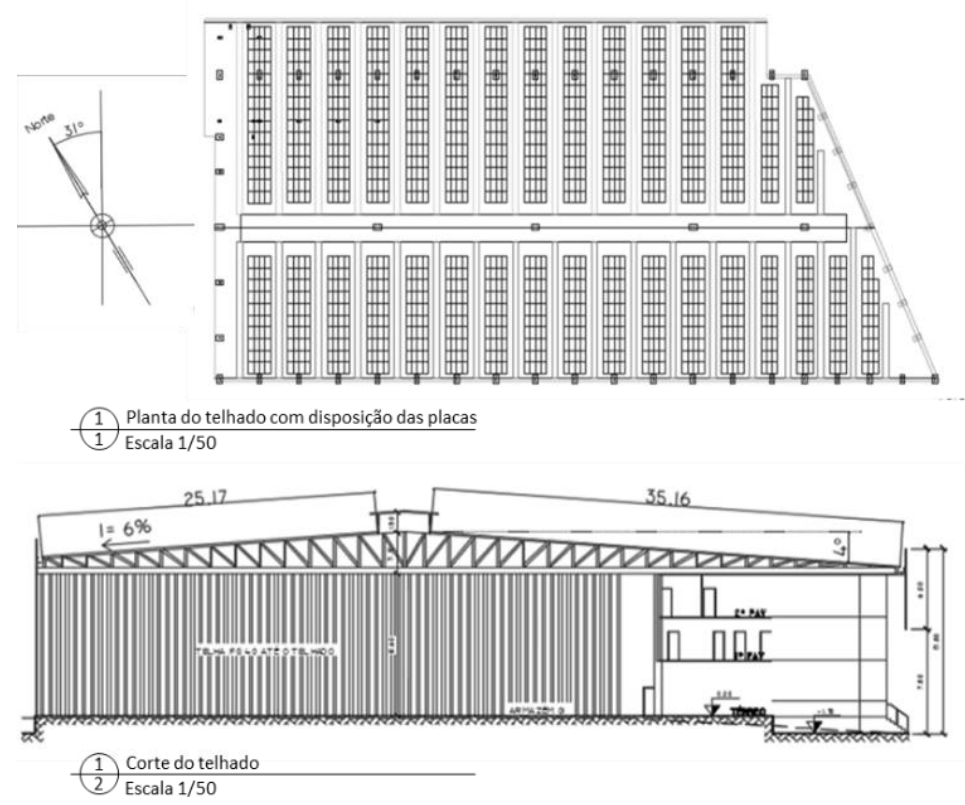

Fonte: Autor (2021)

\subsection{Dados paramétricos}

Além dos dados construtivos e da posição geográfica do telhado do armazém, informações dos componentes do sistema como, placas solares e inversores, e informações do consumo elétrico do imóvel, precisam ser inseridos no simulador PVsyst 7.1.

Na escolha das placas solares, optou-se pelo módulo CS3W-410P fabricado pela Canadian Solar (2021) com $410 \mathrm{Wp}$ de potência, eficiência de 20,67\%, medindo $1,048 \mathrm{~m} \times 2,108 \mathrm{~m}$ e $24,90 \mathrm{~kg}$ por módulo, ou 11,27kg/m². Importante salientar que a NBR8800 (2008), no anexo B, alínea B5, determina uma sobrecarga mínima em telhados de $0,25 \mathrm{kN} / \mathrm{m}^{2}\left(25,49 \mathrm{Kg} / \mathrm{m}^{2}\right)$. Os módulos ocupam $3.256 \mathrm{~m}^{2}$ do telhado, totalizando 1.473 módulos, sendo 835 placas solares na orientação norte e 638 placas na orientação sul.

O inversor escolhido, foi o QS1-1200W, fabricado pela APsystems (Casa Do MicroInversor, 2021) com frequência de saída de $50 / 60 \mathrm{~Hz}$, podendo conectar até 4 módulos fotovoltaicos. Para o projeto serão necessários 387 inversores com potência de 1.200W.

As informações de consumo foram obtidas na fatura emitida pela concessionária LIGHT, em 2019, cedida pela empresa que opera o armazém logístico. $\mathrm{O}$ armazém está classificado como um consumidor de média tensão com tarifas diferenciadas dependendo do horário do consumo elétrico, Horário Fora de Ponta (HFP) ou Horário de Ponta (HP), que para a concessionária da Cidade do Rio de Janeiro vai de 17:30h até 20:30h. A energia consumida é classificada em energia ativa e reativa. O sistema fotovoltaico deve utilizar a energia gerada para abater o consumo mensal no mesmo horário de geração. Como a energia solar fotovoltaica é gerada durante o dia, deve ser compensada no consumo de energia ativa em horário fora de ponta (HFP). Havendo sobra, esse saldo poderá ser utilizado para reduzir o consumo no outro horário tarifário, após a aplicação de um fator de ajuste, uma vez que a valor tarifário é diferenciado. Esse fator de ajuste tarifário 
(FA) é a relação entre a tarifa de energia no horário onde a energia solar é gerada (HFP) e a tarifa de energia consumida em HP, expressa pela equação 1 (ANEEL, 2016):

$\mathrm{FA}=(\mathrm{T} \mathrm{HFP}) /(\mathrm{T} \mathrm{HP})$

Na Tabela 1 estão dispostos o consumo mensal do armazém para energia ativa e reativa nos dois horários de consumo. Também está discriminado o consumo de energia total ajustado que representa a energia que deverá ser compensada pela geração fotovoltaica já com o fator de ajuste aplicado, totalizando 263.269kWh/ano. É importante salientar que a energia reativa não é compensada pela energia solar.

Tabela 1 - Consumo elétrico do armazém logístico de acordo com a fatura de energia emitida pela Concessionária.

\begin{tabular}{|c|c|c|c|c|c|c|c|c|c|c|c|c|c|c|}
\hline kWh & JAN & FEV & MAR & ABR & MAI & JUN & JUL & AGO & SET & OUT & NOV & DEZ & MEDIA & TOTAL \\
\hline $\begin{array}{l}\text { Energia Ativa } \\
\text { HFP } \\
\end{array}$ & 16.196 & 15.811 & 16.597 & 16.209 & 16.823 & 16.082 & 13.005 & 17.797 & 12.445 & 15.249 & 14.082 & 15.904 & 15.517 & 186.200 \\
\hline \begin{tabular}{l|} 
Energia Ativa \\
HP (17:30-20:30)
\end{tabular} & 1.165 & 1.345 & 1.905 & 1.946 & 2.063 & 2.224 & 2.832 & 2.374 & 1.740 & 2.065 & 1.557 & 1.634 & 1.904 & 22.850 \\
\hline \begin{tabular}{|l|} 
Energia \\
Reativa HFP \\
\end{tabular} & 0 & 0 & 0 & 0 & 0 & 0 & 0 & 0 & 0 & 0 & 0 & 0 & 0 & 0 \\
\hline \begin{tabular}{|l} 
Energia \\
Reativa HP
\end{tabular} & 865 & 961 & 971 & 829 & 1.027 & 959 & 945 & 1.084 & 817 & 1.010 & 944 & 1.052 & 955 & 11.464 \\
\hline $\begin{array}{l}\text { Consumo } \\
\text { Energia Ativa } \\
\text { HP AJUSTADO }\end{array}$ & 3.929 & 4.536 & 6.425 & 6.564 & 6.958 & 7.501 & 9.552 & 8.007 & 5.869 & 6.965 & 5.251 & 5.511 & 6.422 & 77.069 \\
\hline $\begin{array}{l}\text { Consumo de } \\
\text { Energia Total } \\
\text { AJUSTADO }\end{array}$ & 20.125 & 20.347 & 23.022 & 22.773 & 23.781 & 23.583 & 22.557 & 25.804 & 18.314 & 22.214 & 19.333 & 21.415 & 21.939 & 263.269 \\
\hline
\end{tabular}

Fonte: Light - Adaptado pelo autor (2020)

\section{RESULTADOS E DISCUSSÃO}

Os dados de irradiação solar a partir da localização geográfica e das informações construtivas do telhado, gerados pelo Meteonorm 7.3, são apresentados na Figura 5 com uma maior irradiação em janeiro e uma menor em junho, $5,85 \mathrm{kWh} / \mathrm{m}^{2}$.dia e $3,22 \mathrm{kWh} / \mathrm{m}^{2}$.dia respectivamente. Assim como acontece com outras fontes renováveis, como a eólica e as hidroelétricas a fio d'água que não possuem estoques reguladores, deve-se observar a intermitência na geração fotovoltaica, devido à variação da irradiação solar diária e ao longo do ano. Desta forma, enfatiza-se a importância da complementaridade das fontes energéticas. 
Figura 5 - Irradiação solar diária média

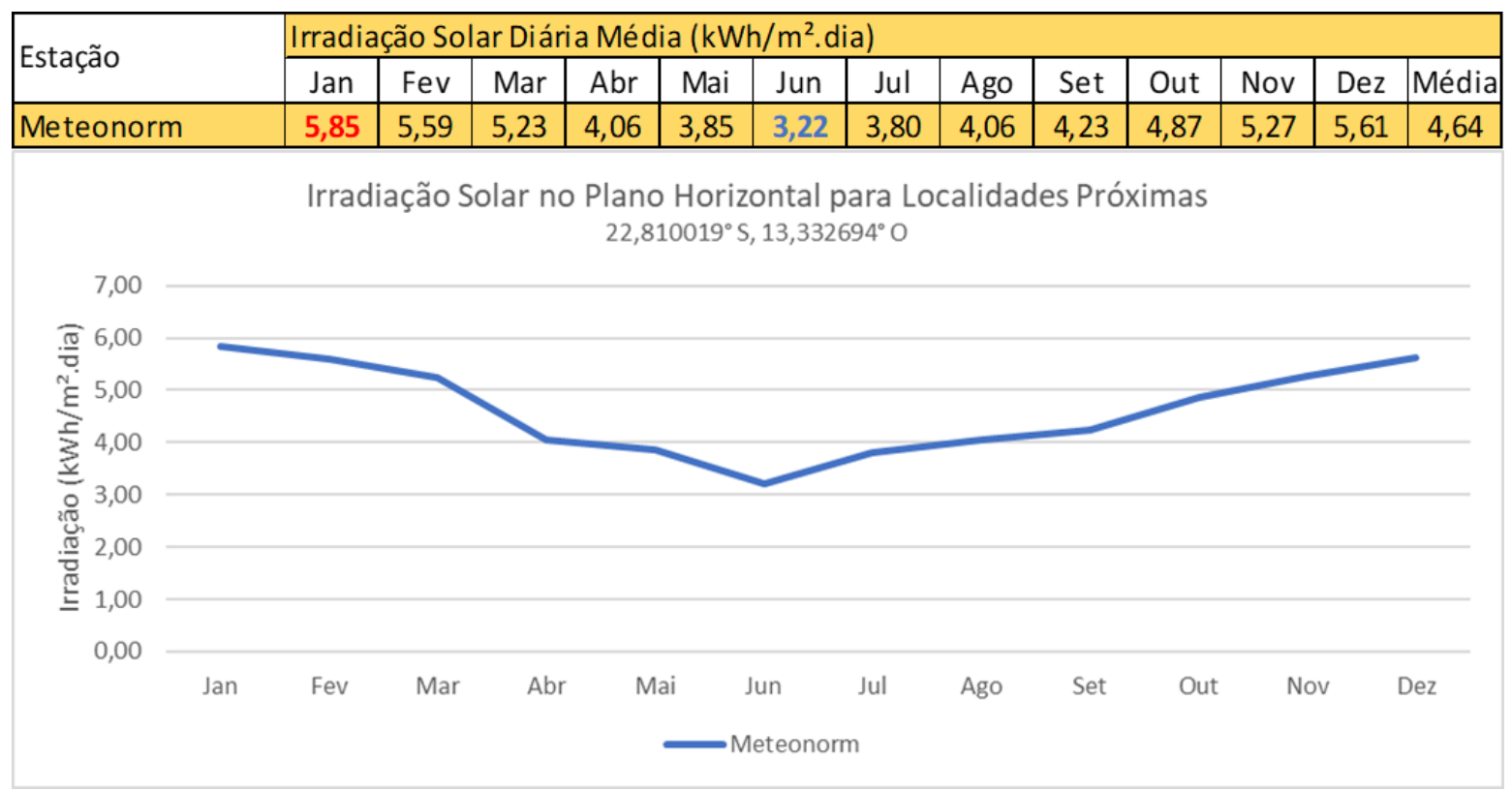

Fonte: Meteonorm 7.3 - adaptado pelo autor (2020)

Com essas configurações, o sistema com 1473 módulos de 410wp, é capaz de gerar uma potência nominal de $604 \mathrm{kWp}$. Essa capacidade de geração classifica o armazém, como uma miniusina de energia solar.

Conforme o gráfico gerado pelo simulador PVsyst 7.1, mostrado na Figura 6, o sistema produz uma energia útil de $3,83 \mathrm{kWh} / \mathrm{kWp} /$ dia. As perdas totais somam $0,81 \mathrm{kWh} / \mathrm{kWp} /$ dia, e apresenta um índice de performance de $82,50 \%$.

Figura 6: Grafico de perdas e Índice de Performance.
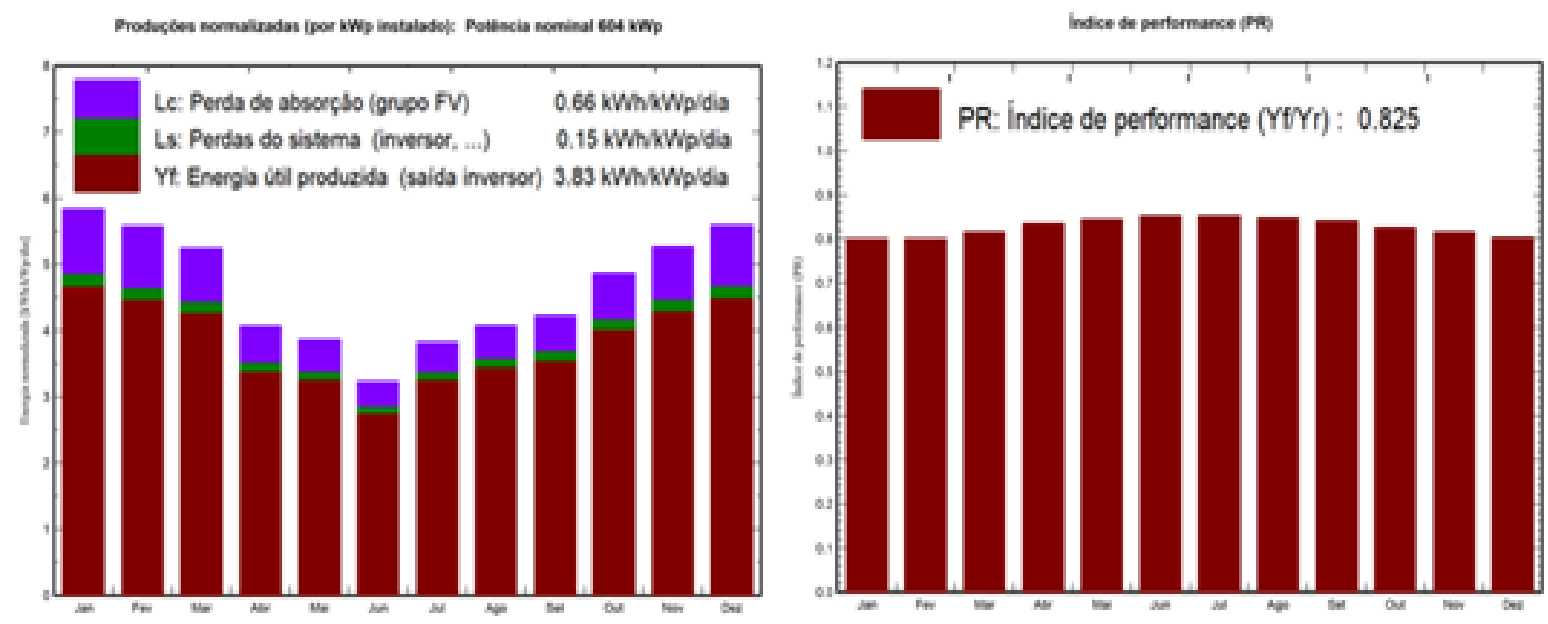

Fonte: PVsyst 7.1 (2021) 
A Tabela 2, parte do relatório do PVsyst 7.1, mostra uma geração de energia fotovoltaica líquida, após as perdas, de $843,8 \mathrm{MWh} / \mathrm{ano}$, para o primeiro ano. Dos $186.200 \mathrm{kWh} /$ ano consumidos de energia ativa fora da ponta, $118.621 \mathrm{kWh} /$ ano são consumidos direto do sistema solar e $725.164 \mathrm{kWh} /$ ano são injetados na rede. Da energia injetada na rede, $144.647 \mathrm{kWh} /$ ano são usados para compensação na fatura de energia. Desta forma, existe um excedente a ser distribuído de $580.517 \mathrm{kWh} /$ ano, no primeiro ano de geração.

Tabela 2 - Principais resultados da produção do sistema fotovoltaico no armazém logístico

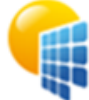

Variante: Nova variante da simulaçăo

\section{PVsyst V7.1.4}

VCO, Data da simulaçăo: 18/02/21 18:42 com v7.1.4

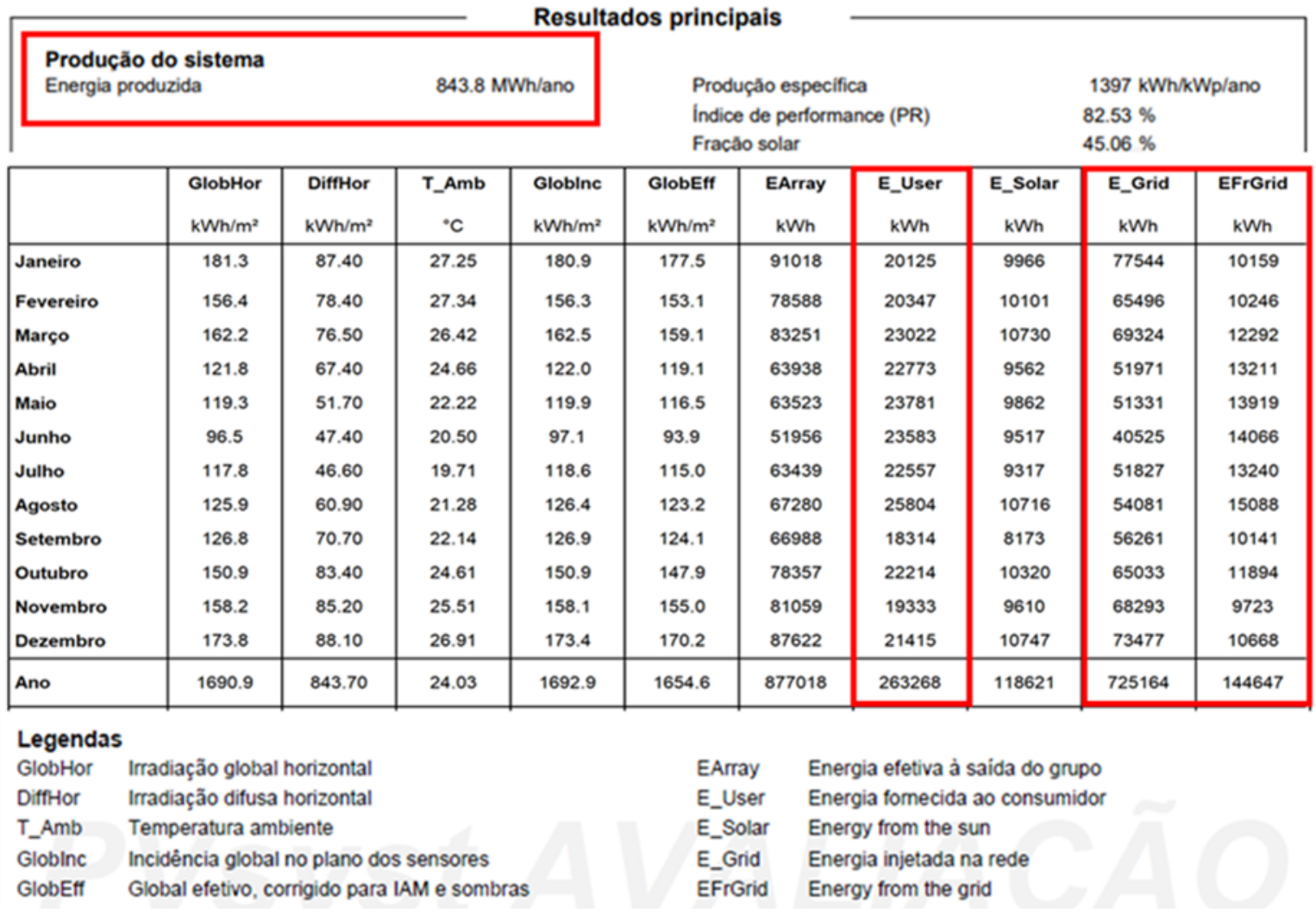

Fonte: PVsyst 7.1 (2021)

Para os 25 anos seguintes, durante a vida útil do sistema, ainda há que se considerar a perda por desgaste natural de 0,8\%/ano em média, informada pelo simulador, reduzindo a produção de energia como mostrado na Figura 7. Desta forma, no último ano de vida útil do sistema, a geração de energia fotovoltaica líquida será de $715.698 \mathrm{kWh} / \mathrm{ano}$. Considerando a energia consumida diretamente do sistema solar e a energia compensada na rede constantes ao longo dos 25 anos, a energia excedente a ser distribuída no último ano será de $457.578 \mathrm{kWh}$, resultando numa energia excedente média anual de 524.526kWh/ano. 
Figura 7 - Produção de energia ao longo da vida útil do sistema

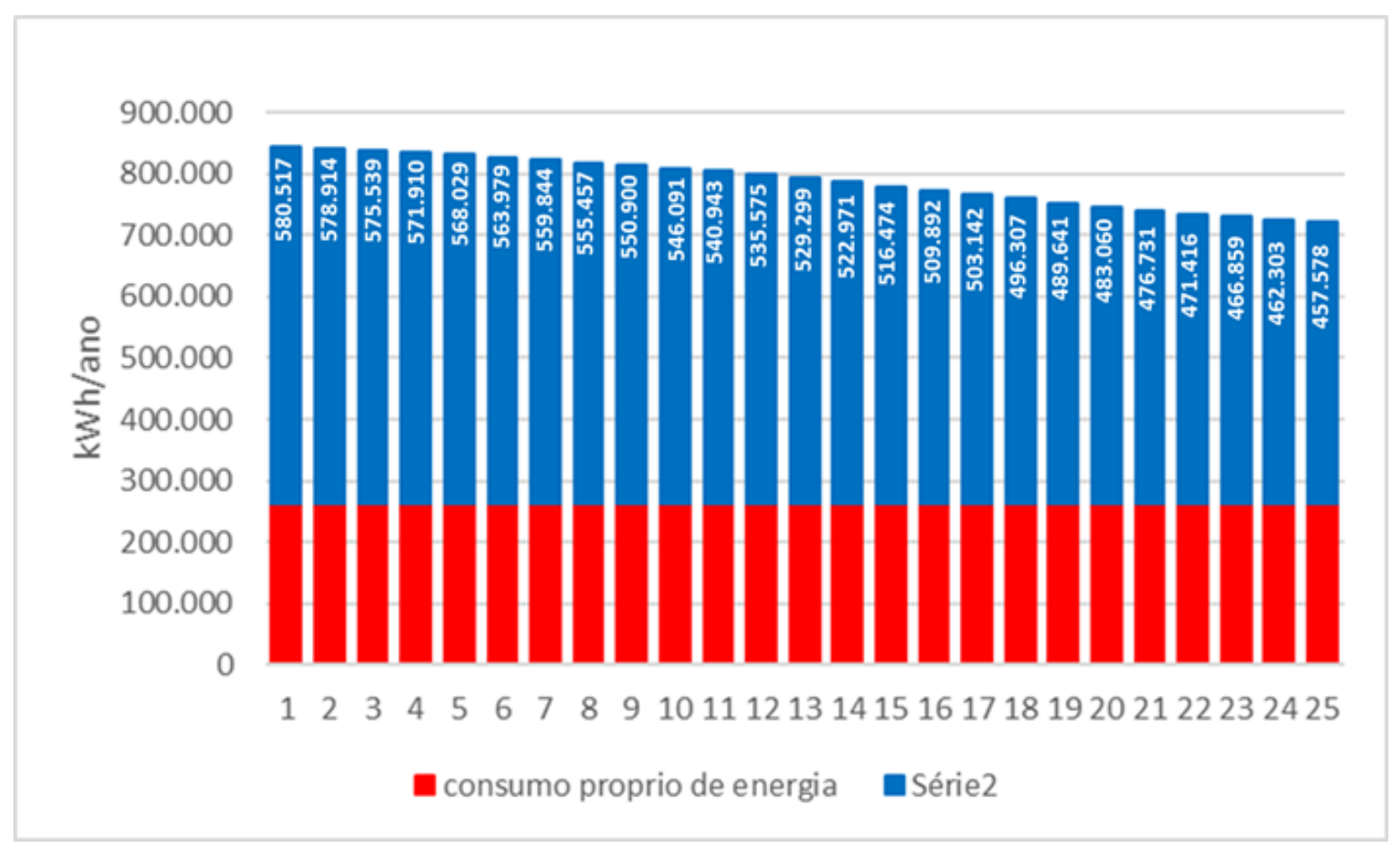

Fonte: PVsyst 7.1 - Adaptado pelo autor (2021)

\section{CONCLUSÕES E RECOMENDAÇÕES}

Este artigo analisou o potencial fotovoltaico de sistemas instalados em telhados de armazéns logísticos por possuírem características singulares, aliado ao fato de estarem inseridos no espaço urbano, junto aos consumidores finais, para serem usados como miniusinas de energia solar para distribuição elétrica. Os resultados indicaram que no armazém logístico analisado, para os $3.256 \mathrm{~m}^{2}$ de placas instaladas gerando em média $524.526 \mathrm{kWh} /$ ano de energia excedente, cada metro quadrado de sistema instalado fornece para a rede elétrica $161 \mathrm{kWh} / \mathrm{ano}$, sendo capaz de atender 175 residências com consumo médio de $3.000 \mathrm{kWh} / \mathrm{ano}$ durante 25 anos.

A partir dos resultados e considerando o universo logístico nos centros urbanos, que tem o CBRE Group, Inc (2017 apud XPIN, 2017) operando no Estado do Rio de Janeiro com 2,55 milhões de $\mathrm{m}^{2}$ de armazéns logísticos, a utilização de miniusinas solares nesses edifícios, resguardadas as características vistas anteriormente, tem o potencial de atender 55.500 residências, podendo atrair investimentos para o setor elétrico e promover estratégias de incentivo a produção de energias sustentáveis.

Contudo, os resultados estão sujeitos a limitações. O potencial elétrico de cada edifício está sujeito a posição geográfica e a inclinação do telhado. Também os telhados existentes para suporte do sistema fotovoltaico, precisam ser avaliados.

Novos estudos podem dar continuidade a este trabalho a fim de verificar a viabilidade econômica do sistema, a forma de contratação da energia elétrica pelos consumidores finais e como se comportam telhados em posições geográficas distintas em relação ao potencial de geração fotovoltaica das cidades. 


\section{AGRADECIMENTOS}

Os autores agradecem o apoio da Universidade Federal do Rio de Janeiro e do Armazém Logístico que cedeu sua fatura de consumo elétrico.

\section{REFERÊNCIAS}

ANEEL Agência Nacional de Energia Elétrica. Cadernos Temáticos ANEEL. Micro e Minigeração Distribuída. Sistema de Compensação de Energia Elétrica. 2ª ed. Brasília: ANEEL, 2016. Disponível em: $<$ https://www.aneel.gov.br/documents/656877/14913578/Caderno+tematico+Micro+e+Minigera\%C3\%A7\% C3\%A3o+Distribuida+-+2+edicao/716e8bb2-83b8-48e9-b4c8-a66d7f655161?version=1.3>. Acesso em: 17 fev. 2021.

CANADIAN SOLAR. Catálogo eletrônico de Painel Solar Fotovoltaico 410W - CS3W-410P. Disponível em: $\quad<$ https://www.canadiansolar.com/wp-content/uploads/2019/12/Canadian_Solar-DatasheetHiKu_CS3W-P_EN.pdf>. Acesso em: 21 jan. 2021.

CASA DO MICROINVERSOR. Catálogo eletrônico de micro-inversor APsystems - QS1-1200W. Disponível em: <https://microinversor.com.br/produto/micro-inversor-apsystems-qs1-220v-monobifasico/?v=9a5a5f39f4c7>. Acesso em: 21 jan. 2021

IBGE INSTITUTO BRASILEIRO DE GEOGRAFIA E ESTATÍSTICA. Brasil em Números. v. 21. Rio de Janeiro: IBGE, 2013. 392 p.

METEONORM Software. Versão 7.3. Meteotest, 2020. Disponível em: $<$ https://meteonorm.com/en/download>. Acesso em: 15 jan. 2021.

MME MINISTÉRIO DE MINAS E ENERGIA. Boletim Mensal de Monitoramento do Sistema Elétrico Brasileiro - Dezembro 2019. Brasília: 2020. Disponível em: $<$ http://www.mme.gov.br/web/guest/secretarias/energia-eletrica/publicacoes/boletim-de-monitoramentodo-sistema-eletrico/2019/>. Acesso em: 28 mar. 2020.

NBR 8800. Projetos de Estrutura de Aço e de Estruturas Mistas de Aço e Concreto de Edifícios. 2a . ed. Rio de Janeiro: ABNT, 2008. 237 p.

ONS OPERADOR NACIONAL DO SISTEMA ELÉTRICO. Histórico da Operação. Energia Armazenada (ERA \%). Disponível em: <http://www.ons.org.br/Paginas/resultados-da-operacao/historico-daoperacao/energia_armazenada.aspx>. Acesso em: 10 mai. 2021.

PBMC Painel Brasileiro de Mudanças Climáticas. Mudanças climáticas e cidades: relatório especial do painel brasileiro de mudanças climáticas - 2016. Rio de Janeiro: COPPE/UFRJ. Disponível em: <http://www.pbmc.coppe.ufrj.br/documentos/Relatorio_UM_v10-2017-1.pdf>. Acesso em: 29 abr. 2021.

PVSYST Photovoltaic Sofware. Versão 7.1. Fundation PVsyst, 2020. Disponível em: <https://www.pvsyst.com/download-pvsyst/>. Acesso em: 15 jan. 2021.

XPIN Fundo de Investimento Imobiliário. Mercado de Galpões Industriais e Logísticos. 2017. Disponível em: <https://xpin.riweb.com.br/show.aspx?idMateria=oJUAMayn5DWq54xRVRroGw==>. Acesso em: 11 mai. 2020. 